\title{
Mobile RNAs - the magical elf traveling between plant and the associated organisms
}

\author{
Shuo Zhang and Zhi Hong*
}

\begin{abstract}
RNA interfering (RNAi) is mediated by small non-coding RNAs (sRNAs) and efficiently silence gene expression at the posttranscriptional level in eukaryotes. In addition to functioning within a cell, such silencing RNA signals can also be transmitted over a long distance or even cross-species, therefore named mobile RNAs. Recent studies have demonstrated that mobile RNAs have the potential to suppress interspecies gene expression when plants suffer from biotic stress. In this review, we discuss the role of mobile RNAs as silencing signals transmitted between host plants and fungi, parasitic plants, and mammals. The potential applications of mobile RNAs on plant protection to resist the pests and pathogens by bioengineering strategy are also prospected.
\end{abstract}

Keywords: Mobile RNA, Cross-species regulation, HIGS, SIGS

\section{Background}

Plants direct or indirectly provide food and energy for almost all living things on earth. As vast majority of plants are sessile, it is quite important for plants to set up the multiple layers of defense mechanisms to respond and resist the surrounding adverse environment. Recently, RNAi has been proved to play important roles in fine-tuning of mechanisms for innate immune responses and gene regulation for plant development against various biotic and abiotic stresses, such as pathogen, pests, extreme temperature and salt stress [1-4].

RNAi phenomenon is first reported in Caenorhabditis elegans in 1993 [5] and soon it is found ubiquitous in eukaryotes to regulate various biological processes $[3,6]$. RNAi is mediated by sRNAs and associated Argonaute (AGO) family proteins [6]. In plant, sRNAs are classified into two classes: small interfering RNA (siRNA) and microRNA (miRNA). Except the different biological origin of precursor, both classes share the similar biogenesis process and function mechanism, spliced by DICER-like (DCL) family from primary transcript, methylated by HUA ENHANCER1 at miRNA 3' ends,

\footnotetext{
* Correspondence: zhihong@nju.edu.cn

State Key Laboratory of Pharmaceutical Biotechnology, NJU Advanced

Institute for Life Sciences (NAILS), School of Life Sciences, Nanjing University, 163 Xianlin Road, Nanjing 210046, Jiangsu, China
}

exported to cytoplasm by HASTY, and loaded into AGO protein to trigger target mRNA degradation or translational inhibition via complementary pairing $[2,7]$.

Many studies have elucidated that sRNAs are not bound in a single cell but can spread to neighbor cells and even move over a long distance [8-11]. Such transmission can occur between tissues and even trans-species to silence the gene expression or direct epigenetic modification, thus such sRNAs are also called mobile RNAs [11-14]. Cell-to-cell spreading of sRNAs is thought through the plasmodesmata. Comparably, long-distance transmission of sRNAs is believed via the vascular system $[11,12,15]$. These mobile RNAs act as message carriers between the sessile plants and the associated species, supporting that individual species are not isolated, but are associated with each other. Here, we summarize several recent discoveries related to sRNA-mediated cross-species communications between plants and parasitic plants, fungi as well as mammals. The potential applications of mobile RNAs in agriculture are also prospected.

\section{Fungal infection and plant immunity}

Plants are often suffered from fungal infection during growth. In plants, pathogen attacks induce multiple layers of host immune response such as pathogen-associated molecular pattern (PAMP)-triggered immunity (PTI) and 
pathogen protein effector-triggered immunity (ETI). The evolutionary arms race also stimulates fungi to develop strategies to outmaneuver the host immune system [1618]. Recent study has demonstrated that sRNAs in fungi hijack host RNAi pathways to suppress plant immunity for fungi invasion (Fig. 1a).

Botrytis cinerea, a necrotrophic fungus, infects almost all vegetables and fruit crops and cause enormous losses in agriculture [19]. Recent studies have showed over hundreds of unique sRNAs derived from $B$. cinerea are detected in both leaves and fruits of Arabidopsis and tomato (Solanum lycopersicum) in the early stage of $B$. cinerea infection [20]. The targets of three enriched siRNAs ( $B c$-siR3.1, $B c$-siR3.2 and $B c$-siR5) in plant hosts are predicted, in which Arabidopsis mitogen-activated protein kinase genes MPK1 and MPK2, a cell wall-associated kinase (WAK), a peroxiredoxin (PRXIIF), and the tomato MPK-kinase kinase 4 (MAPKKK4), are functionally related to plant innate immunity [20]. Moreover, it is confirmed that these sRNAs are loaded into host AGO1, the key protein in the RNA induced silence complex (RISC), to specifically knockdown the target gene expression and inhibit plant immunity. Correspondingly, Arabidopsis AGO1 mutant ago1-27 inoculated with B. cinerea, exhibits reduced susceptibility and the knockout of DCL1 and DCL2 to inhibit the biogenesis of $B c$-sRNAs in $B$. cinerea leads to a reduction in infection virulence as well. Most recently, the same group demonstrates that the expression level of $B c$-siR37 is induced during the B. cinerea infection and eight predicted Arabidopsis target genes are suppressed in which three targets are related to disease susceptibility to $B$. cinerea [21], suggesting sRNA may also act as virulence effector by fungus to subvert host immunity $[18,22]$.

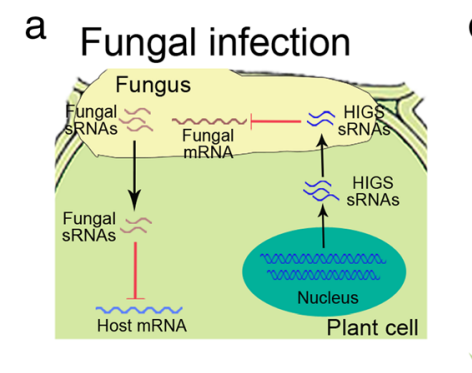

\section{d SIGS}
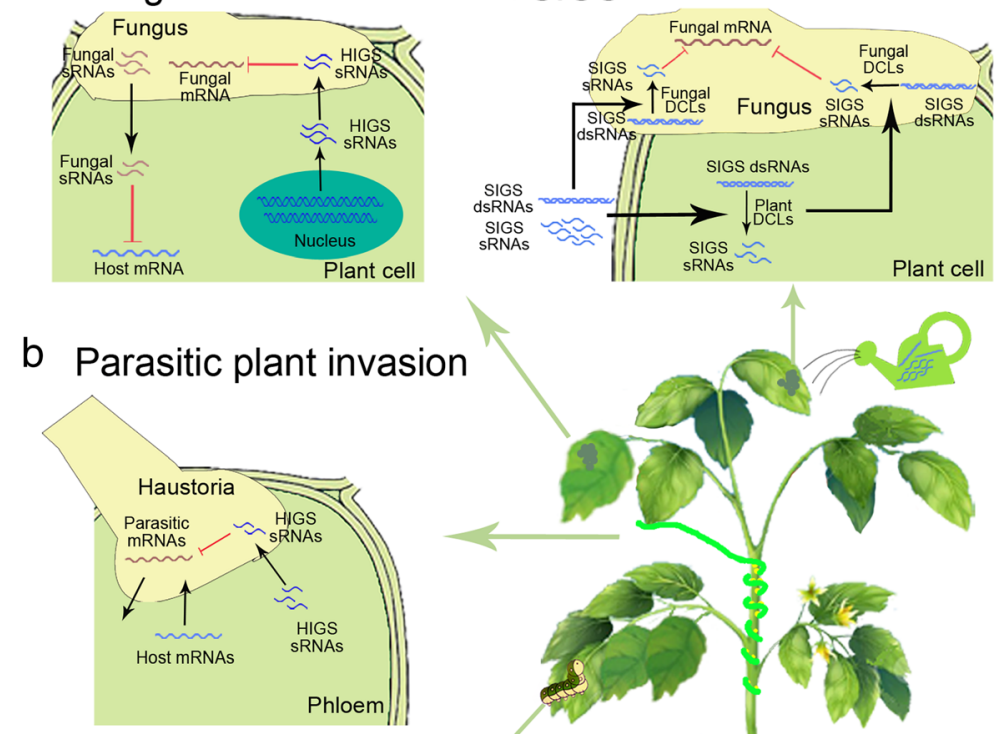

\section{Animal ingestion}
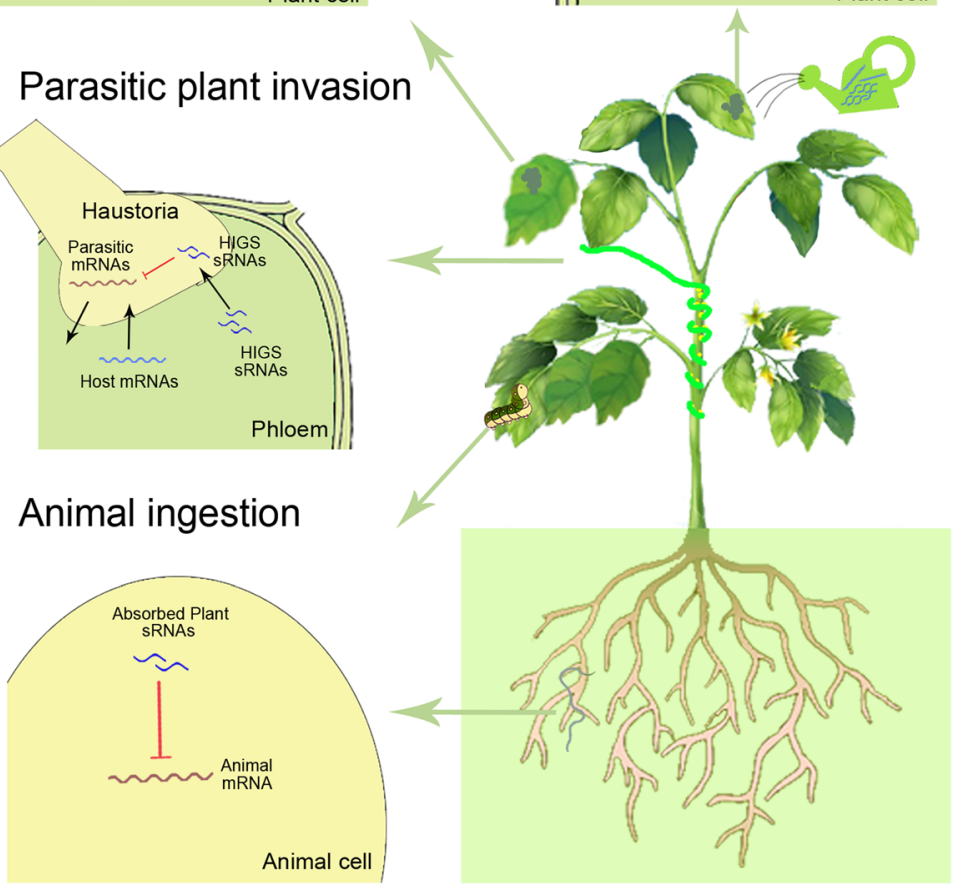

Fig. 1 Mobile RNAs transmit genetic information between plant and the associate organisms. a Fungal sRNAs can act as pathogen effectors to suppress host gene expression. Host-induced gene silencing (HIGS) inhibits pathogen infection and virulence gene expression through hostderived sRNAs. $\mathbf{b}$ Transmission of mRNAs is bi-directional between hosts and parasitic plants through haustoria. Host sRNAs can enter and regulate the gene expression of parasitic plants (HIGS). c Plant-derived sRNAs are able to be ingested by animal to regulate the biological processes. d Spray-Induced Gene Silencing (SIGS) directly suppress fungal gene expression by externally spraying dsRNAs or sRNAs on plant surface. These transferred dsRNAs may be processed into sRNAs under the function of fungal or plant DCL proteins 


\section{Parasitic plants and nutrient uptake from host}

Another important threat for plants comes from Cuscuta (dodder). The genus Cuscuta has more than 200 species and they attach to xylophyta, liana, and important economic crops. The annual economic losses caused by the destruction of dodder are considerable [23, 24].

Dodders penetrate the host plants to get the nutrients with the specialized organs, haustoria [25]. The vascular of haustoria allows the transfer of water, nutrients and also macromolecules including mRNAs, proteins, and even pathogens [23, 26, 27]. Several host RNA transcripts from Arabidopsis, pumpkin or tomato have been detected in dodders, respectively (Fig. 1b) [27-31]. Surprisingly, these translocated RNA molecules are quite stable and keep detectable at a long distance far from the attached sites $(25-30 \mathrm{~cm})$ in dodders [26, 28, 31]. Further study using next-generation sequencing reveals that such RNA movements between host and parasitic plants are bidirectional (Fig. 1b) [26]. Near the haustorial attachment area in the parasite stem, there is about $1 \%$ of the RNAs derived from Arabidopsis, while in the reverse direction $0.6 \%$ of RNAs in the Arabidopsis stem are of Cuscuta origin. The similar RNA movements are also found between Cuscuta and tomato though at a relatively low rate [26].

Further evidences supporting the sRNA can transmit come from the observation of exogenous gene expression. When Triphysaria versicolor expressing the $\beta$-glucuronidase (GUS) reporter gene attach to the bioengineered lettuce expressing GUS siRNA sequences, the level of GUS decreased in Triphysaria versicolor root tissue near the attachment site and the decrease of gene expression is gradually abolished with the increase of distance [32]. Similarly, siRNA sequences in the host effectively down-regulate the expression of acetyl-CoA carboxylase, mannose 6-phosphate reductase or SHOOT MERISTEMLESS-like (STM) in the parasite [3335]. In particular, host expressing STM-RNAi significantly inhibits the dodders growth, showing limited growth, promoted flowering, and decreased seed production [34] (Fig. 1b), suggesting that the mobile RNAi signals have the great potential to limit parasitic plant growth and reproduction [36].

\section{The genetic media from plant to mammals}

Since Zhang et al. report that plant miRNAs accumulate in serum and organs to regulate gene expression in mammal [37], the debate over the small RNA molecules acting as signaling molecules for trans-species regulation emerges. Many studies are subsequently conducted to evaluate this finding since it opens a new horizon to investigate the potential cross-regulation and even co-evolution between mammal and plant (Fig. 1c) [38-40].

Compared to mammal, miRNAs or siRNAs in plant are 2'-O-methylated at 3' ends which are thought to contribute to their stability in vivo $[41,42]$. The methylation at 3' ends renders plant miRNAs resistant to periodate, which differ from mammalian miRNAs that bearing free 2' and 3' hydroxyl groups [43]. According to this feature, Zhang et al. confirm the miRNAs detected in mammalian serum are bona fide plant miRNAs. They find miR168a, one of most abundant plant miRNAs present in human serum can directly bind to the coding sequence of low-density lipoprotein receptor adaptor protein 1 (LDLRAP1) in liver cells and influence the uptake of low-density lipoprotein from the blood in mouse. This report provides evidence that food-derived exogenous plant miRNAs could pass the gastrointestinal tract and enter into the mammalian organs through circulatory system to regulate target gene expression and biological processes [37].

Several pieces of evidence from another two independent labs also support plant small RNAs can cross-regulate mammalian gene expression [44, 45]. When $A p c^{\mathrm{Min} /+}$ mouse, model of colon cancer, are oral administrated with synthetic suppressor sRNAs with methylation at the $2^{\prime}$ position of the ribose of the 3' terminus, mimic of the plant miRNA, the tumor burden is substantially reduced [44]. Another study reports that plant miR159 is present in human sera and tumor tissues, and its level is inversely correlated with breast cancer morbidity and progression. Most of identified miR159 was abundant in extracellular vesicles [45]. Synthetic miR159 sequences suppress the proliferation of breast cancer cells through binding to the 3' untranslated region (3' UTR) of human Transcription Factor 7 mRNA. When continuously fed the xenograft-tumor mice with synthetic 2 '-O-methylated miR159, the tumor growth is significantly inhibited compared with those treated with scrambled control oligonucleotides.

Honeysuckle (Lonicera japonica) is a widely used Chinese herb to treat influenza for thousands of years. It has been demonstrated that miR2911, an atypical miRNA encoded by honeysuckle genome, is abundant in decoction [46]. Feeding mice with honeysuckle decoction, the obvious increase of miR2911 content can be observed in both serum and lung. Plant miR2911 can bind and suppress $\mathrm{H} 1 \mathrm{~N} 1, \mathrm{H} 5 \mathrm{~N} 1$, and H7N9 viral replication and even reduce $\mathrm{H} 5 \mathrm{~N} 1$-induced mortality. It can be inferred that miRNAs are important and effective components in Chinese herbs.

With the discovery that the exogenous miRNAs can regulate mammalian gene expression, it implies us that we not only absorb its nutrients, but also inherit regulatory information when consuming food [47]. In turn, it can be expected that plants have great potential to produce the components beneficial to human health and disease treatment in an effective and affordable way [39]. 


\section{Benefits from bioengineering mobile sRNAs}

The discovery of mobile RNAs acting as cross-species regulatory signals to silence gene expression offers a possible strategy to protect economic plants against pathogens and pests. Host-induced gene silencing (HIGS) is host sRNAs moving to parasitic species to silence gene expression [48].

Due to the existence of haustoria [23, 27], sRNAs can transmit from host to parasitic plants to disrupt normal haustorial growth and reduce the infectivity of parasitic plants by debilitating the establishment of the initial haustoria or plasmodesmata connections between the host and the parasite [32-35]. HIGS strategy is also used to control plant diseases and insect pests. In 2007, Mao et al. [49] showed that regenerated plants expressing double stranded RNAs (dsRNAs) targeting mono-oxygenase gene CYP6AE14 of cotton bollworm (Helicoverpa armigera) significantly impaired larvae tolerance to gossypol, the secondary metabolite with antibacterial and insecticidal activities [50, 51]. Subsequently, many studies have been explored to apply HIGS to protect crops from fungi, parasitic plants, pests and nematodes (Fig. 1a-c) [52-59]. Screening of target genes is important for RNAi effect (52). It is believed that genes expressing in midgut and those that are vital for pest growth and development are optimal [60-62]. In addition, Renata et al. report that for western corn rootworm (WCR, Diabrotica virgifera virgifera LeConte), the length of dsRNA is also important for silencing efficiency [63].

However, it is impossible to genetically modify all of the economically important crops to against various biotic threats. It is quite interesting to see that whether direct spray of siRNAs have the effect on pathogen or pest.

Recently, Koch et al. demonstrate that spray-induced gene silencing (SIGS) is an effective gene silencing method to control Fusarium graminearum infections on barley (Fig. 1d) [64]. F. graminearum causes head blight and seedling blight in important cereal crops including rice, maize, and wheat. Spraying 791-nt long dsRNAs on barley leaves, targeting three fungal CYP51 genes responsible for fungal membrane integrity [65], prevents disease development and alleviates the host damage. Intriguingly, the fall of fungal CYP51 transcripts and the presence of dsRNAs are detected in the segments away from the spraying sites, indicating that the long dsRNAs can transmit along the conductive system in plant. Surprisingly, dsRNAs of CYP51 can persistently exist for $168 \mathrm{~h}$ at the local or non-sprayed distal segments [64]. On the other hand, it is found that the ingested dsRNAs need fungal DCL1 gene to generate the final sRNAs in F. graminearum. Using the $d c l-1$ mutant, the infection of F. graminearum seems not effected in the presence of the silencing dsRNAs. However, when treated with high concentration of dsRNA-derived sRNAs against CYP51, the fungus is strongly suppressed in both the local and the distal leaf segments [64]. Wang et al. report when externally applied dsRNAs or sRNAs targeting DCL1 and DCL2 of B. cinerea on plants, the fungal infection is controlled and these dsRNAs and sRNAs can protect vegetables and fruits against B. cinerea for up to 8 days [66]. The authors claim that several sRNAs acting as virulence effectors are required to be processed by $B$. cinerea DCL proteins. Further investigations of DCLs function involved in SIGS are necessary. Notably, both of the studies demonstrate that non-native silencing sequences can be maintained for a relatively long duration in fungus $[64,66]$. In addition, spraying a GFP-specific $720 \mathrm{nt}$ long dsRNAs on barley leaves also effectively suppress the expression of GFP in F. graminearum strain [64].

Although the exact mechanisms about how these external RNAs are taken up and transmitted among the organisms are unclear, the HIGS and SIGS have shown the great potential to protect plant from pathogen or pests $[64,66,67]$ and the "RNA insecticide" is already on the way [68]. Most recently, the product of Monsanto, DvSnf7 dsRNA against western corn rootworm has been approved in USA. However, as these external supplied RNAs are also ingested by host plants, it should be carefully taken into consideration that the designed sequences may cause dysregulation of host endogenous genes.

\section{Conclusions and perspectives}

Individual species in the ecosystem are not isolated but communicate to each other. Mobile RNAs-medicated gene silencing between the organism and their habitat has been well documented as regulatory signal. It can be predicted that the mobile RNAs serving as a kind of 'talking language' among the diverse individuals is universally exist. An important advantage using mobile RNAs as a tool for crop protection is that these RNAi signals are non-cell-autonomous, acting both at local and systemic levels [34], which makes it has broad application prospects in agriculture and human health. On the other hand, although many important results have been achieved, the knowledge about how long dsRNAs are processed by fungal DCLs and the mobile RNAs transmit between individuals are still less known. Several technical problems also need to be solved, such as the stability of sRNAs, the potential off-target effect and drug resistance. Therefore, a better understanding of the molecular mechanisms of mobile RNAs transfer among diverse species and the hijack of the target will greatly helpful to further development of RNAi technology. 


\section{Abbreviations}

3' UTR: The 3' untranslated region; AGO: Argonaute; Bc: Botrytis cinerea; DCL: DICER-like; dsRNAs: double stranded RNAs; ETI: Pathogen protein effector-triggered immunity; GUS: $\beta$-glucuronidase; HIGS: Host-induced gene silencing; LDLRAP1: Low-density lipoprotein receptor adaptor protein 1; MAPKKK4: MPK-kinase kinase 4; miRNA: microRNA; MPK: Mitogen-activated protein kinase gene; PAMP: Pathogen-associated molecular pattern; PRXIIF: Peroxiredoxin; PTI: Pathogen-associated molecular pattern triggered immunity; RISC: RNA induced silence complex; RNAi: RNA interfering; SIGS: Spray-induced gene silencing; siRNA: small interfering RNA; sRNAs: small non-coding RNAs; STM: SHOOT MERISTEMLESS-like; WAK: Cell wall-associated kinase; WCR: Western corn rootworm (Diabrotica virgifera virgifera LeConte)

\section{Acknowledgements}

Not applicable.

\section{Funding}

This work was partially supported by grants from the National Natural Science Foundation--Outstanding Youth Foundation of China (No.31322008) and the National Basic Research Program of China (No. 2014CB542300).

\section{Availability of data and materials}

Not applicable.

\section{Authors' contributions}

ZH and SZ conceived and wrote the paper. Both authors read and approved the final manuscript

\section{Ethics approval and consent to participate}

Not applicable.

\section{Consent for publication}

Not applicable.

\section{Competing interests}

The authors declare that they have no competing interests.

\section{Publisher's Note}

Springer Nature remains neutral with regard to jurisdictional claims in published maps and institutional affiliations.

Received: 19 May 2017 Accepted: 7 January 2019

Published online: 14 February 2019

\section{References}

1. Jones-Rhoades MW, Bartel DP, Bartel B. MicroRNAs and their regulatory roles in plants. Annu Rev Plant Biol. 2006;57:19-53.

2. Voinnet O. Origin, biogenesis, and activity of plant microRNAs. Cell. 2009; 136(4):669-87.

3. He L, Hannon GJ. Micrornas: small RNAs with a big role in gene regulation. Nat Rev Genet. 2004:5(7):522-31.

4. Lodish HF, Zhou B, Liu G, Chen CZ. Micromanagement of the immune system by microRNAs. Nat Rev Immunol. 2008;8(2):120-30.

5. Lee RC, Feinbaum RL, Ambros V. The C-elegans heterochronic gene lin-4 encodes small RNAs with antisense complementarity to lin-14. Cell. 1993; 75(5):843-54.

6. Krol J, Loedige I, Filipowicz W. The widespread regulation of microRNA biogenesis, function and decay. Nat Rev Genet. 2010;11(9):597-610.

7. Ha M, Kim VN. Regulation of microRNA biogenesis. Nat Rev Mol Cell Bio. 2014;15(8):509-24

8. Dunoyer $\mathrm{P}$, Himber C, Voinnet O. DICER-LIKE 4 is required for RNA interference and produces the 21-nucleotide small interfering RNA component of the plant cell-to-cell silencing signal. Nat Genet. 2005;37(12): $1356-60$

9. Brosnan CA, Mitter N, Christie M, Smith NA, Waterhouse PM, Carroll BJ. Nuclear gene silencing directs reception of long-distance mRNA silencing in Arabidopsis. Proc Natl Acad Sci U S A. 2007;104(37):14741-6.

10. Chitwood DH, Timmermans MCP. Small RNAs are on the move. Nature. 2010;467(7314):415-19.
11. Brosnan CA, Voinnet O. Cell-to-cell and long-distance siRNA movement in plants: mechanisms and biological implications. Curr Opin Plant Biol. 2011; 14(5):580-7.

12. Sarkies P, Miska EA. Small RNAs break out: the molecular cell biology of mobile small RNAs. Nat Rev Mol Cell Bio. 2014;15(8):525-35.

13. Molnar A, Melnyk CW, Bassett A, Hardcastle TJ, Dunn R, Baulcombe DC. Small silencing RNAs in plants are mobile and direct epigenetic modification in recipient cells. Science. 2010;328(5980):872-5.

14. Weiberg $A$, Bellinger $M$, Jin $H$. Conversations between kingdoms: small RNAs. Curr Opin Biotechnol. 2015;32:207-15.

15. Dunoyer P, Melnyk C, Molnar A, Slotkin RK. Plant Mobile Small RNAs. Csh Perspect Biol. 2013;5(7):a017897.

16. Jones JDG, Dangl JL. The plant immune system. Nature. 2006;444(7117): 323-9.

17. Chisholm ST, Coaker G, Day B, Staskawicz BJ. Host-microbe interactions: shaping the evolution of the plant immune response. Cell. 2006;124(4): 803-14.

18. Weiberg $A$, Wang $M$, Bellinger $M$, Jin $H$. Small RNAs: a new paradigm in plant-microbe interactions. Annu Rev Phytopathol. 2014;52:495-516.

19. Dean R, Van Kan JAL, Pretorius ZA, Hammond-Kosack KE, Di Pietro A, Spanu PD, Rudd JJ, Dickman M, Kahmann R, Ellis J, et al. The top 10 fungal pathogens in molecular plant pathology. Mol Plant Pathol. 2012; 13(4):414-30.

20. Weiberg A, Wang M, Lin FM, Zhao H, Zhang Z, Kaloshian I, Huang HD, Jin H. Fungal small RNAs suppress plant immunity by hijacking host RNA interference pathways. Science. 2013;342(6154):118-23.

21. Wang M, Weiberg A, Dellota E Jr, Yamane D, Jin H. Botrytis small RNA BCsiR37 suppresses plantdefense genes by cross-kingdom RNAi. RNA Biol. 2017;14(4):421-8.

22. Wang $M$, Weiberg $A$, Jin $H$. Pathogen small RNAs: a new class of effectors for pathogen attacks. Mol Plant Pathol. 2015;16(3):219-23.

23. Kim G, Westwood JH. Macromolecule exchange in Cuscuta-host plant interactions. Curr Opin Plant Biol. 2015;26:20-5.

24. Costea M, Tardif FJ. The biology of Canadian weeds. 133. Cuscuta campestris Yuncker, C-gronoviiWilld. ex Schult., C-umbrosa Beyr. ex Hook., Cepithymum (L.) L. and C-epilinumWeihe. Can J Plant Sci. 2006:86(1):293-316.

25. Vaughn KC. Dodder hyphae invade the host: a structural and immunocytochemical characterization. Protoplasma. 2003:220(3-4):189-200.

26. Kim G, LeBlanc ML, Wafula EK, dePamphilis CW, Westwood JH. Plant science. Genomic-scale exchange of mRNA between a parasitic plant and its hosts. Science. 2014;345(6198):808-11.

27. Leblanc M, Kim G, Westwood JH. RNA trafficking in parasitic plant systems. Front Plant Sci. 2012;3:203.

28. LeBlanc M, Kim G, Patel B, Stromberg V, Westwood J. Quantification of tomato and Arabidopsis mobile RNAs trafficking into the parasitic plant Cuscuta pentagona. New Phytol. 2013;200(4):1225-33.

29. Roney JK, Khatibi PA, Westwood JH. Cross-species translocation of mRNA from host plants into the parasitic plant dodder. Plant Physiol. 2007;143(2): 1037-43.

30. Westwood JH, Roney JK, Khatibi PA, Stromberg VK. RNA translocation between parasitic plants and their hosts. Pest Manag Sci. 2009;65(5):533-9.

31. David-Schwartz R, Runo S, Townsley B, Machuka J, Sinha N. Long-distance transport of mRNA via parenchyma cells and phloem across the hostparasite junction in Cuscuta. New Phytol. 2008;179(4):1133-41.

32. Tomilov AA, Tomilova NB, Wroblewski T, Michelmore R, Yoder Jl. Transspecific gene silencing between host and parasitic plants. Plant J. 2008; 56(3):389-97.

33. Bandaranayake PC, Yoder Jl. Trans-specific gene silencing of acetyl-CoA carboxylase in a root-parasitic plant. Mol Plant-Microbe Interact. 2013;26(5): 575-84.

34. Alakonya A, Kumar R, Koenig D, Kimura S, Townsley B, Runo S, Garces HM Kang J, Yanez A, David-Schwartz R, et al. Interspecific RNA interference of SHOOT MERISTEMLESS-like disrupts Cuscuta pentagona plant parasitism. Plant Cell. 2012:24(7):3153-66.

35. Aly R, Cholakh H, Joel DM, Leibman D, Steinitz B, Zelcer A, Naglis A, Yarden $\mathrm{O}$, Gal-On A. Gene silencing of mannose 6-phosphate reductase in the parasitic weed Orobanche aegyptiaca through the production of homologous dsRNA sequences in the host plant. Plant Biotechnol J. 2009; 7(6):487-98

36. Dang YK, Yang OY, Xue ZH, Liu Y. RNA interference in fungi: pathways, functions, and applications. Eukaryot Cell. 2011;10(9):1148-55. 
37. Zhang L, Hou D, Chen X, Li D, Zhu L, Zhang Y, Li J, Bian Z, Liang X, Cai X, et al. Exogenous plant MIR168a specifically targets mammalian LDLRAP1: evidence of cross-kingdom regulation by microRNA. Cell Res. 2012;22(1): 107-26.

38. Lukasik A, Zielenkiewicz P. Plant MicroRNAs-novel players in natural medicine? Int J Mol Sci. 2016;18(1):9.

39. Xie W, Weng A, Melzig MF. MicroRNAs as new bioactive components in medicinal plants. Planta Med. 2016;82(13):1153-62.

40. Hirschi KD, Pruss GJ, Vance V. Dietary delivery: a new avenue for microRNA therapeutics? Trends Biotechnol. 2015:33(8):431-2.

41. Ji $\amalg$, Chen XM. Regulation of small RNA stability: methylation and beyond. Cell Res. 2012;22(4):624-36.

42. Zhang X, Cozen AE, Liu Y, Chen Q, Lowe TM. Small RNA modifications: integral to function and disease. Trends Mol Med. 2016;22(12):1025-34

43. Yu B, Yang Z, Li J, Minakhina S, Yang M, Padgett RW, Steward R, Chen X. Methylation as a crucial step in plant microRNA biogenesis. Science. 2005; 307(5711):932-5.

44. Mlotshwa S, Pruss GJ, MacArthur JL, Endres MW, Davis C, Hofseth LJ, Pena MM, Vance $V$. A novel chemopreventive strategy based on therapeutic microRNAs produced in plants. Cell Res. 2015;25(4):521-4.

45. Chin AR, Fong MY, Somlo G, Wu J, Swiderski P, Wu X, Wang SE. Crosskingdom inhibition of breast cancer growth by plant miR159. Cell Res. 2016; 26(2):217-28.

46. Zhou Z, Li X, Liu J, Dong L, Chen Q, Liu J, Kong H, Zhang Q, Qi X, Hou D, et al. Honeysuckle-encoded atypical microRNA2911 directly targets influenza A viruses. Cell Res. 2015:25(1):39-49.

47. Jiang M, Sang $X$, Hong Z. Beyond nutrients: food-derived microRNAs provide cross-kingdom regulation. BioEssays. 2012;34(4):280-4

48. Nowara D, Gay A, Lacomme C, Shaw J, Ridout C, Douchkov D, Hensel G, Kumlehn J, Schweizer P. HIGS: host-induced gene silencing in the obligate biotrophic fungal pathogen Blumeria graminis. Plant Cell. 2010;22(9):3130-41.

49. Mao YB, Cai WJ, Wang JW, Hong GJ, Tao XY, Wang LJ, Huang YP, Chen XY. Silencing a cotton bollworm P450 monooxygenase gene by plant-mediated RNAi impairs larval tolerance of gossypol. Nat Biotechnol. 2007;25(11):1307-13.

50. Wang X, Howell CP, Chen F, Yin J, Jiang Y. Gossypol--a polyphenolic compound from cotton plant. Adv Food Nutr Res. 2009;58:215-63.

51. Stipanovic RD, Lopez JD, Dowd MK, Puckhaber LS, Duke SE. Effect of racemic and (+)- and (-)-gossypol on the survival and development of Helicoverpa zea larvae. J Chem Ecol. 2006;32(5):959-68.

52. Rodrigues TB, Figueira A. Management of insect pest by RNAi-A new tool for crop protection. RNA Interference. InTech Open, Croatia. 2016; 371-90.

53. Auer C, Frederick R. Crop improvement using small RNAs: applications and predictive ecological risk assessments. Trends Biotechnol. 2009;27(11):644-51.

54. Weiberg A, Jin H. Small RNAs--the secret agents in the plant-pathogen interactions. Curr Opin Plant Biol. 2015;26:87-94.

55. Swevers L, Smagghe G. Use of RNAi for control of insect crop pests. In: Arthropod-Plant Interactions: novel insights and approaches for IPM Springer-Verlag, Dordrecht, The Netherlands. 2012;pp. 177-97.

56. Li H, Guan R, Guo H, Miao X. New insights into an RNAi approach for plant defence against piercing-sucking and stem-borer insect pests. Plant Cell Environ. 2015;38(11):2277-85.

57. Duan CG, Wang CH, Guo HS. Application of RNA silencing to plant disease resistance. Silence. 2012;3(1):5.

58. Majumdar R, Rajasekaran K, Cary JW. RNA interference (RNAi) as a potential tool for control of mycotoxin contamination in crop plants: concepts and considerations. Front Plant Sci. 2017:8:200.

59. Knip M, Constantin ME, Thordal-Christensen H. Trans-kingdom cross-talk: small RNAs on the move. PLoS Genet. 2014;10(9):e1004602.

60. Huvenne H, Smagghe G. Mechanisms of dsRNA uptake in insects and potential of RNAi for pest control: a review. J Insect Physiol. 2010;56(3):227-35.

61. Lim ZX, Robinson KE, Jain RG, Chandra GS, Asokan R, Asgari S, Mitter N. Diet-delivered RNAi in Helicoverpa armigera - progresses and challenges. J Insect Physiol. 2016:85:86-93.

62. Zha WJ, Peng XX, Chen RZ, Du B, Zhu LL, He GC. Knockdown of midgut genes by dsRNA-transgenic plant-mediated RNA interference in the hemipteran insect Nilaparvata lugens. PLoS One. 2011;6(5).

63. Bolognesi R, Ramaseshadri P, Anderson J, Bachman P, Clinton W, Flannagan R, llagan O, Lawrence C, Levine S, Moar W, et al. Characterizing the mechanism of action of double-stranded RNA activity against Western corn rootworm (Diabrotica virgifera virgifera LeConte). PLoS One. 2012;7(10) p. e47534
64. Koch A, Biedenkopf D, Furch A, Weber L, Rossbach O, Abdellatef E, Linicus L, Johannsmeier J, Jelonek L, Goesmann A, et al. An RNAi-based control of fusarium graminearum infections through spraying of long dsRNAs involves a plant passage and is controlled by the fungal silencing machinery. PLoS Pathog. 2016;12(10) p. e1005901.

65. Koch A, Kumar N, Weber L, Keller H, Imani J, Kogel KH. Host-induced gene silencing of cytochrome P450 lanosterol C14 alpha-demethylase-encoding genes confers strong resistance to fusarium species. Proc Natl Acad Sci U S A. 2013;110(48):19324-9.

66. Wang $M$, Weiberg A, Lin FM, Thomma BP, Huang HD, Jin H. Bidirectional cross-kingdom RNAi and fungal uptake of external RNAs confer plant protection. Nat Plants. 2016;2:16151.

67. Wang $\mathrm{M}_{\text {, Thomas }} \mathrm{N}_{\text {, Jin }} \mathrm{H}$. Cross-kingdom RNA trafficking and environmental RNAi for powerful innovative pre- and post-harvest plant protection. Curr Opin Plant Biol. 2017:38:133-41.

68. Wang $M$, Jin HL. Spray-induced gene silencing: a powerful innovative strategy for crop protection. Trends Microbiol. 2017;25(1):4-6.

\section{Ready to submit your research? Choose BMC and benefit from:}

- fast, convenient online submission

- thorough peer review by experienced researchers in your field

- rapid publication on acceptance

- support for research data, including large and complex data types

- gold Open Access which fosters wider collaboration and increased citations

- maximum visibility for your research: over $100 \mathrm{M}$ website views per year

At BMC, research is always in progress.

Learn more biomedcentral.com/submissions 